\title{
Editorial
}

\section{A new co-Editor-in-Chief for Veterinary Research}

We are happy to welcome Professor Bruno B. Chomel who has accepted to replace J.-M. Aynaud as co-editor-in-Chief of our journal. J.-M. Aynaud held this function since 1997. He has greatly contributed to the development of the journal. In addition, his very good knowledge of the animal health research environment in France has been invaluable. Last but not least, it has always been a pleasure for the Editorial office to work with him, and we sincerely thank him for his contribution to Veterinary Research during these years.

Professor Bruno B. Chomel received his Doctorate of Veterinary Medicine from the Veterinary School of Lyon (France) in 1978. He also earned degrees in Microbiology from the Institut Pasteur de Paris (1981) and in Immunology from the University Claude Bernard of Lyon (1982). He received his Ph.D. in 1984 and his Research Director's degree in 1989. From 1985 to 1987, Bruno B. Chomel acquired a specialisation in epidemiology at the Center for Disease Control in Atlanta, Georgia (USA), where he served as an Epidemic Intelligence Officer. He is currently a Professor of Zoonoses at the School of Veterinary Medicine in Davis (University of California), where he teaches epidemiology of infectious diseases and in particular zoonoses, which are increasingly important public health concerns all over the world. Professor B. Chomel has an international reputation as one of the best specialists in the field of epidemiology of zoonoses. We are pleased to benefit from his expertise in continuing to ensure and develop a high quality editorial policy for Veterinary Research. An editorial presenting the future projects of the new editorial office will be published in a future issue. 